\title{
State University Students' Learning Locations and Remote Learning Challenges During the COVID-19 Pandemic
}

\author{
Cristie Ann L. Jaca* \\ Cebu Technological University - Main Campus, Cebu City, Philippines
}

\begin{abstract}
Online classes during the COVID-19 pandemic were confronted with varied challenges. Examples are the technological and economic issues that university students had to deal with, especially in developing countries such as the Philippines. Data were collected from two groups $(\mathrm{N}=60)$ of Bachelor in Secondary Education (BSEd) English major classes during the second semester of the 2020 academic year. This paper presents the participants' demographic profile, their learning locations, and their remote learning challenges in attending online classes during the COVID-19 pandemic. The study employed mixed-methods research. For the quantitative part, student participants completed a survey questionnaire using Google Forms, where they identified key challenges while attending their online classes during the COVID-19 pandemic. A quantitative design was used to describe the demographic profile of the participants in terms of age, gender, type of senior high school (SHS) they graduated from, devices used for online learning, internet service provider, and the location of online learning. A qualitative research design was used to determine the challenges encountered by participants in online learning. Thematic analysis using Braun and Clarke's (2006) model was employed to analyze the qualitative data gathered on remote learning challenges. Findings revealed three major themes of student online learning experiences. The first was a poor and unstable internet connection, together with finding a reliable signal to be able to connect to the internet. The second and third were limited economic capabilities leading to restricted data or no load balance, and a non-conducive learning environment, respectively. The state university students in the Philippines grapple with these challenges that interfere with their studies instead of embracing more opportunities to engage in meaningful remote learning experiences.
\end{abstract}

Keywords: challenges; COVID-19; online classes; remote learning; state university students 


\section{Introduction}

Sing and Thurman (2019) defined online learning as "learning experiences in synchronous or asynchronous environments using different devices (e.g., mobile phones, laptops, etc.) with internet access". Almost all facets and venues of education were significantly affected by the COVID-19 pandemic, which paved the way for a seemingly passing over from face-to-face teaching and learning to online learning. The unexpected outbreak of COVID-19 has affected every sphere of life, especially education (Cï̆erci, 2020). The use of technology for online teaching and learning paved the way for flexible delivery of instruction. The 2030 Agenda for Sustainable Development adopted by all United Nations (UN) member states in 2015 identified 17 sustainable development goals (SDGs) that need to be achieved primarily for developing countries. Fourth on the list is quality education, which has recently been challenged by the COVID-19 pandemic. During the COVID-19 pandemic, concerns relating to communication, student assessment, use of technological tools, online experience, pandemic-associated anxiety or stress, time management, and technophobia were all noted as obstacles to online medical education (Rajab et al., 2020). Computer technology has a major influence on the "flat world", as depicted in Friedman's book The world is flat. The implication here is that the teaching-learning process needs to cope with the ever-changing technology that will provide students with a technology-rich environment. The essay on teaching language arts in a flat world provides ideas on promoting innovation skills (Burke, 2010).

In developing countries such as the Philippines, particularly in some public schools and state universities in the country, students have limited access to the internet due to straitened circumstances. Despite the students' desire to use technology to meet their course requirements and improve their digital literacy skills, they have limited or no access to online data (Gebremichael \& Jackson, 2006). This highlights the need for information professionals from developed countries to actively participate in the fight against information poverty in developing countries (Gebremichael \& Jackson, 2006). E-learning bears relevance with a number of arguments. Some of the topics discussed in relation to online pedagogy include accessibility, cost, flexibility, learning pedagogy, lifelong learning, and policy (Dhawan, 2020). Becker et al. (2020) investigated remote learning methods and challenges schools and communities face in providing essential support, particularly for people with mental health disorders and learning disabilities. Morgan (2020) argued that some schools do not have enough resources to provide pupils with learning opportunities and that not all children have access to the internet at home. Ferri et al. (2020) also recognized several technological, pedagogical, and societal issues.

The use of educational technology to enhance the teaching and learning process to achieve relevant education is experiencing challenges. University students in developing countries in Asia are confronted with issues related to technology usage in the delivery of instruction. In the Philippines, students enrolled in state universities have to cope with the economic impact of the COVID-19 pandemic. As these students attend online classes during the pandemic, they experience 
challenges in connectivity coupled with financial and family-related issues that affect their learning experiences in online classes and their academic standing.

Online delivery of instruction has reached the height of its prominence due to the COVID-19 pandemic as schools have had to transform face-to-face classes to online teaching or blended learning for health and safety reasons. This has brought about particular challenges, such as the technological and economic issues university students have to deal with, especially in developing countries such as the Philippines. Not much has been recorded about the impact of COVID-19 lockdown restrictions on tertiary education and learning in developing countries. As such, there is a need to document learning experiences as a basis for proposing action plans to improve instructional delivery in this flexible learning era.

\section{Objectives of the Study}

The study examined state university students' challenges in attending online classes in their respective localities amidst the COVID-19 pandemic.

Specifically, the following objectives were set:

1. To describe the profile of the participants in terms of:

a. age;

b. gender;

c. type of senior high school (SHS) they graduated from;

d. gadgets used for online learning;

e. internet service provider; and

f. location when attending online classes.

2. To determine the challenges that students encountered in attending online classes.

3. To propose initiatives to help students in their online classes.

\section{Literature Review}

As academic stakeholders and educational researchers seek to build new pedagogies to address the promise of digital technology within existing curriculum and assessment systems, progressive changes in literacy pedagogy are being made (Walsh, 2010). During the globalization period, there has been a race to master, develop, and implement new technology. One of the most effective methods to use technology in education is to use education-based programs such as Google Classroom, which offers a new teaching environment (Sudarsana et al., 2019). Technology increases collaboration (Costley, 2014), primarily when students collaborate to develop outputs or acquire ideas from one another by reading each other's work (Keser et al., 2011). Nonetheless, Chang (2016) indicated that a one-to-one technological program has been used to improve critical thinking, creativity, collaboration, and communication (the four C's of twentyfirst century skills). However, there are cases when the lack of understanding, analysis, and reflection on the use of these learning tools may affect their implementation and the expected outcomes (Abeysekera \& Dawson, 2014). Concerns around pace and user experience have also been aired (Heggart \& Yoo, 2018). Moreover, Kaufman (2014) emphasized the increasingly urgent application of technology for teaching and learning purposes and discussed prospects for improving technological acquisition. 
Students and teachers might be affected differently by different types of media and technologies used in the classroom. According to Christensen (2002), needsbased technology-integration education has a direct and beneficial impact on teacher attitudes such as computer phobia, perceived importance of computers, and pleasure of computers.

McKnight et al. (2016) documented digital instructional strategies teachers use to enhance and transform student learning and align that use with learning research. Ertmer et al. (2015) proposed that teachers must have the mindset that "teaching is not effective without the appropriate use of information and communication technologies (ICT) resources to facilitate learning".

There is sufficient research showing the advantages of using internet-based technology in improving education and developing skills (Christensen, 2002; Dogruer et al., 2011; Geladze, 2015; Kamba, 2007; McKnight et al., 2016). This is because information technologies have penetrated almost all spheres of educational fields for both teachers and students as they use the internet for their academic responsibilities, personal utilization, and research tasks (Dogruer et al., 2011; Geladze, 2015; Kamba, 2007). Technology also increases student collaboration (Costley, 2014), primarily when they work together to create projects or learn from each other by reading the work of their peers.

Different stakeholders have reacted differently to the adoption of Google Classroom. Studies have begun to show that Google Classroom can work in a unidirectional manner, serving both teachers and students' perceptions, understandings, and successful engagement in various classroom abilities (Saeed Al-Maroof \& Al-Emran, 2018). At Al Buraimi University College (BUC) in Oman, Saeed Al-Maroof and Al-Emran (2018) looked at the elements that influence students' acceptance of Google Classroom. They found that both the perceived ease of use (PEOU) and perceived usefulness (PU) of Google Classroom have a positive impact on the behavioral intention to use them.

Iftakhar (2016) investigated and reported on the overall view of Google Classroom, its features, and some adoption factors, such as organizational, social, personal, and technological dimensions. Analysis of the results indicated that through Google Classroom, one can effectively understand and evaluate teachers and learners' perceptions in ensuring quality teaching and learning. On the other hand, Azhar and Iqbal's (2018) study revealed that teachers felt that Google Classroom should be used as a facilitation tool only that can be used for document management and essential classroom management, without having a significant impact on teaching methodologies.

The educational damage wrought by COVID-19 on schools affected learners and teachers equally. What makes the situation even bleaker are the lack of support from the authorities and the ineptness of the educational system to deal with and confront the pandemic in an attempt to keep education afloat. South Africa's uneven educational system can be used as example, with some schools being 
supported, while others are not. Due to a lack of or insufficient infrastructure, too many schools are unable to move their courses online. In addition, a scarcity of laptops or high internet prices keep students from accessing classes for longer periods of time, even if schools can move them online. Although people live in the same country, they do not have the same resources. Therefore, the current necessity for a shift to online learning serves as a reminder (Reiersgord, 2020).

The Philippines, a third-world country, was caught unprepared by the outbreak of COVID-19. The education sector struggled to provide quality education to every student. The challenges are simply overwhelming for both the teacher and the student. First-generation students especially encountered incredible difficulty in virtual classes when higher education switched to online learning due to inadequate technology and space to complete coursework. During the pandemic, about $15 \%$ of first-generation students had to look after children, compared to $7 \%$ of other students. In addition, $18 \%$ of first-generation students had to care for adults, compared to $12 \%$ of other students (Zalaznick, 2020).

According to the International Telecommunications Union (ITU) of the UN, the first barrier to online learning is the digital divide. Only $47 \%$ of people in underdeveloped nations accessed the internet before the COVID-19 pandemic, compared to $86 \%$ in developed countries. As the chair of Culture and Education for Peace at the Universidad Técnica Particular de Loja (Ecuador) pointed out, the pandemic has affected at least $60 \%$ of the student population, as many students do not have the means or tools to access online instruction. Because COVID-19 has such a large impact, prompt responses are required. Indeed, students in financial hardship are more likely to have limited or no internet access, according to the UNESCO chair of Population, Migrations, and Development of the Sapienza University of Rome (UNESCO, 2020). This is either because they cannot afford a laptop or an internet connection or because they live in areas with poor connectivity.

\section{Methodology}

This study used mixed-methods research that employed both a quantitative and qualitative research design. The study was based on state university students' personal experiences of their remote learning classes. Participants completed a survey questionnaire using Google Forms, where they identified the five key challenges that they encountered while attending their online courses during the COVID-19 pandemic. The data were collected from the two groups of Bachelor in Secondary Education (BSEd) English major classes during the second semester of the 2020 academic year. The results were analyzed using descriptive statistics employing frequency counting and ranking. The participants identified challenges through the multiple-choice questions of the Google Forms questionnaire; the personal online interview supported their answers to validate the responses from the questionnaire. This was done to solicit their personal experiences to provide actual data to explain the phenomenon under study. Participants were able to express their concerns based on their online class experiences. 


\subsection{Research Participants}

The study employed universal sampling or total enumeration involving all sophomore BSEd English major students enrolled during the second semester of the 2020 academic year at Cebu Technological University. The population consisted of 60 students who belonged to the two sections of sophomores, with 30 students in each section.

\subsection{Research Instrument}

A researcher-made survey questionnaire using Google Forms was utilized as the study was conducted during the COVID-19 pandemic (Appendix 1). The first part of the questionnaire contained items seeking data on the participants' demographic profile regarding age, gender, type of SHS they graduated from, devices used for online learning, internet service provider, and location during online learning. Part II of the instrument was a checklist of participants' perceived online learning challenges. The research instrument was content-validated by experts in the teaching of English.

\subsection{Research Procedure}

Permission was sought from the Vice President Academic Affairs to conduct the study. Student participants had to provide informed consent to confirm their voluntary participation in the study. Upon approval, permission from the Ethics Review Board of Cebu Technological University was sought. The researchermade questionnaire was then sent to the appropriate online platforms through Google Forms. Once data had been retrieved, it was analyzed and interpreted utilizing proper quantitative and qualitative statistical tools.

\subsection{Data Analysis}

To determine the demographic profile of the participants in terms of age, gender, type of SHS they graduated from, devices used for online learning, internet service provider, and the location of online learning, descriptive statistics was employed using modes, frequencies, and percentages presented in frequency distributions. On the other hand, for analyzing the qualitative data on the results of the challenges that the participants encountered in attending online classes, Braun and Clarke's (2006) thematic analysis was employed. Participants' challenges were validated through an online interview, where they narrated their personal experiences while attending online classes in their respective home residences. A few steps were undertaken to perform the thematic analysis. First, the transcripts were read and reread for familiarization with the data on the challenges met by the participants in attending online classes. Second, initial codes were generated from the significant challenges as highlighted by the participants. Third, themes were searched and reviewed.

\subsection{Ethical Considerations}

Before data collection, approval was sought from the student participants through a consent form that solicited their voluntary participation in this study. Participants were assigned a code to maintain anonymity and confidentiality. Likewise, the data collected through Google Forms were bound to privacy to ensure that it is solely used for academic purposes. 


\section{Results and Discussion}

Owing to the COVID-19 pandemic, university students have had a variety of experiences, especially in developing nations such as the Philippines, where faceto-face instruction has been replaced with remote learning. During the COVID-19 pandemic, students who took online classes experienced a variety of difficulties in delivering information. This section presents the study results represented by three tables reflecting the distribution of participants by age, gender, and type of SHS they graduated from (Table 1), distribution of participants by location (Table 2), and devices used for online learning, including their internet service provider (Table 3). Likewise, qualitative descriptions on remote learning challenges and qualitative feedback on the challenges encountered in attending online classes based on the interview data are also itemized together with the proposed initiatives based on the challenges.

\subsection{Participants' Age, Gender, and Type of Senior High School They Graduated from}

Table 1 presents the distribution of the participants in terms of their age, gender, and type of SHS they graduated from.

Table 1: Distribution of participants by age, gender, and type of senior high school they graduated from

\begin{tabular}{lcc}
\hline \multicolumn{1}{c}{ Age (years) } & Frequency & $\%$ \\
\hline 19 & 8 & 13.33 \\
20 & 39 & 65 \\
21 & 13 & 21.67 \\
Total & 60 & 100 \\
\hline \multicolumn{1}{c}{ Gender } & Frequency & $\%$ \\
Female & 51 & 85 \\
Male & 9 & 15 \\
Total & 60 & 100 \\
\hline Type of SHS graduate & Frequency & $\%$ \\
Public & 44 & 73.33 \\
Private & 16 & 26.67 \\
Total & 60 & 100 \\
\hline
\end{tabular}

The participants were all within the age bracket of 19 to 21 years. The majority of the participants $(65 \%)$ were 21 years old. Of the remainder, $21.67 \%$ were 20 years old and $13.33 \%$ were 19 years old. In terms of gender, there were more female $(85 \%)$ than male $(15 \%)$ participants. These 60 participants were graduates of private and public SHSs in Cebu and Cebu City, Philippines. A predominant number of participants were public high school graduates (73.33\%). The remaining $26.67 \%$ graduated from a private high school within Cebu City and neighboring municipalities in Cebu, Philippines.

\subsection{Participants' Location When Attending Online Classes}

State university students in the Philippines mostly come from low- to middle-income families as education is free and has been democratized to the 
public. During the pandemic, participants went home to their respective home provinces as face-to-face classes had been suspended. Table 2 shows participants' place of origin or hometown, which is also where they attended their online courses.

Table 2: Distribution of participants by location

\begin{tabular}{lcc}
\hline \multicolumn{1}{c}{ Place of origin } & Frequency & $\mathbf{0}$ \\
\hline Carcar City & 2 & 3.33 \\
Cebu City & 11 & 18.33 \\
Lapulapu City & 13 & 21.67 \\
Mandaue City & 8 & 13.33 \\
Naga City & 2 & 3.33 \\
Talisay City & 2 & 3.33 \\
Municipalities of Cebu & 17 & 28.33 \\
Neighboring islands & 5 & 8.33 \\
Total & 60 & 100 \\
\hline \multicolumn{1}{c}{ Place of Origin } & Frequency & $\%$ \\
City & 38 & 63.33 \\
Municipality & 17 & 28.33 \\
Neighboring islands & 5 & 8.33 \\
Total & 60 & 100 \\
\hline
\end{tabular}

Table 2 shows the distribution of participants by location, referring to their place of origin. The majority of the participants were from different Cebu municipalities and within the city. The majority of participants $(63.33 \%)$ were from the city, $28.33 \%$ from the municipality, and $8.33 \%$ from neighboring islands. The participants experienced limited or poor internet connection in their place of residence, leading to difficulty in regularly attending their online classes. This implies that most participants came from different localities with a limited or poor internet connection, leading to difficulty attending their online courses. Their access to their online learning is therefore based on how strong their internet connectivity is. The intermittent connectivity issue and poor internet access are a problem. Likewise, this also reflects the diverse areas from which participants came. Some resided in the city, while others were in their home provinces, located in different barangays in Cebu City and Cebu provinces. Most of these locations encountered connectivity problems due to distance, location, and signal. Thus, this finding confirms the challenges of connectivity. The ITU of the UN stated that the digital divide is the first hurdle that colleges must overcome in order to address the impact of COVID-19 on underprivileged students (UNESCO, 2020).

\subsection{Devices Used During Online Classes}

One of the challenges students experience during online classes is the type of device they use. In most public schools where laptops are a rare commodity, several students use cell phones as their primary medium in attending online classes. That is why their time is limited in working online to meet their class requirements. Table 3 reflects the devices used by the participants for their online courses. The table also reflects the internet service provider participants used. 
Table 3: Devices and internet service provider used for online learning

\begin{tabular}{lcc}
\hline \multicolumn{1}{c}{ Device used } & Frequency & $\%$ \\
\hline Cell phone & 56 & 93.33 \\
Laptop & 1 & 1.67 \\
Both cell phone and laptop & 3 & 5 \\
Total & 60 & 100 \\
\hline Internet service provider & Frequency & $\%$ \\
Cignal & 3 & 5 \\
Globe & 21 & 35 \\
Smart & 20 & 33.33 \\
PLDT & 12 & 20 \\
TM & 1 & 1.67 \\
TNT & 1 & 1.67 \\
PisoWifi & 1 & 1.67 \\
Smart; PLDT & 1 & 1.67 \\
Total & 60 & 100 \\
\hline
\end{tabular}

Table 3 reflects what devices participants used for attending online classes. The device used most was the cellular phone (93.33\%). This implies that the majority of the participants would have had difficulty complying with their course requirements as they would have had to type using their cell phones with limited space and usage possibilities. This means that their access may also have been limited to the resources available at home. Since most participants used cellular phones for their online classes, it was difficult for them to comply with some course requirements that require a lot of typing and other technical features for a particular project. Zalaznick (2020) confirmed that first-generation students encountered greater difficulty in attending virtual classrooms when higher education moved to online learning due to a lack of adequate technology and space to perform course work. At home, some students do not have access to laptop or desktop computers or high-speed internet. In addition, for reasons of technophobia, elderly internet users benefit the least from online education (Nimrod, 2018).

As one participant expressed:

"One of my problems is that my phone is already full of storage - the reason I couldn't easily access or download some of the required apps that will be used during our meeting, such as Microsoft Office and Zoom, since my phone is not updated." (P24)

The use of the mobile device during online classes limits students' opportunity to participate in class and derails the submissions of their schoolwork.

Moreover, the internet service provider that participants used in securing connections also seemed to have troubles regarding connectivity and accessibility. The university reached out to all students and extended help in providing them with Globe connectivity kits. That is why most of the participants (35\%) used Globe as their internet service provider. This was followed by Smart $(33.33 \%)$ and 
PLDT $(20 \%)$, as certain areas are only covered by those service providers. The remaining participants made use of internet service providers that they could afford or that were available in their location.

\subsection{Remote Learning Challenges}

An ongoing reality for a developing country such as the Philippines in the context of continuous online learning is that it has obstacles to overcome. Students experienced varied challenges in their attendance of and participation in online classes. Participants narrated their perspectives as they expressed their personal experiences in their online learning journey amidst the COVID-19 pandemic. Their impressions of their online course specified the challenges they encountered in online learning that led to their absence and tardiness and delayed submissions of assignments and classwork.

\subsection{Qualitative Feedback on the Challenges Encountered in Attending Online Classes Based on the Interview Data}

Thematic analysis by Braun and Clark (2006) was employed to identify themes related to the challenges participants encountered during their online classes. Data familiarization, code creation, topic identification, theme evaluation, theme naming, and report production were all considered as part of the six-phase strategy for a reliable thematic analysis. In a data set, this process includes determining the most important themes and analyzing, arranging, explaining, and reporting them (Braun \& Clarke, 2006). The feedback of participants on the challenges they encountered while attending online classes included connectivity and accessibility issues, academic constraints, mental stress-related issues, and economic limitations that hamper the learning continuum.

In this study, participants expressed their personal experiences in attending online classes amidst the COVID-19 pandemic. Three significant themes were generated: 1) challenging internet connection and signal, 2) low to no budget allocation for data, and 3) inconducive learning environment. These themes are discussed in this section. Excerpts from the participants from the random interviews to validate their responses to the researcher-made questionnaire are used as support.

\subsubsection{Theme 1: Challenging internet connection and signal}

The majority of the participants expressed that they experienced an unstable to no internet connection. This finding is exemplified in the following vignettes:

"First, the most common thing a student would always experience is an unstable internet connection. There were times that I had to wait a couple of minutes before I could rejoin the meeting because there is no internet connection." (P1)

"Internet connectivity is one of my biggest adversaries apart from the weather. Moreover, the demand for technology usage is employed in implementing these classes. The signal is all that matters." (P2)

"My experiences during online classes are my internet connection, blackout, and my mobile phone. First is the internet connection. I crack 
up on this kind of issue because I'm having a hard time attending the synchronous class." (P3)

"I've been having a hard time being in an online class, especially when the internet connection is starting to be unstable. Also, I usually don't understand everything that the teacher discussed." (P7)

"One of the most frustrating encounters during online class is the poor connection." (P10)

"Sometimes there is no internet connection, while most of the time the connectivity is deficient; that's why it is difficult to attend to my online classes." (P15)

5.5.2 Theme 2: Low to no low budget allocation for data

Many participants shared common sentiments on their financial limitations regarding buying internet load/data to attend online classes. The following utterances show these concerns:

"Financial problem is the most struggling thing that I've experienced during this online class. The amount that I consume is more than the costs of my allowance that I have during the face-to-face classes." (P8)

"Sometimes I cannot attend my online classes because I do not have money to buy the internet load/data." (P11)

"One of the problems that I've encountered during online classes is lack of internet load and having an unstable internet connection, wherein sometimes I am having a hard time joining our synchronous meeting. I am also having trouble getting some updates on some of my subjects. In addition, one of my problems is that my phone is already full of storage the reason I couldn't easily access or download some of the required apps that will be used during our meetings, such as Microsoft Office and Zoom, since my phone is not updated and is not suited with this so-called online classes." (P9)

"I have difficulty continuing my online class, because sometimes my internet load is not enough for all my online classes." (P28)

Financial limitations deprive students of consistently joining online classes, since most students would run out of load, thus stopping them from attending online sessions. Some students are also dependent on their meager budget in buying a load or renting an internet station to participate in online classes. The availability of the load or internet data that will allow the students to join online courses has been a consistent concern for many who cannot afford to buy the load.

\subsubsection{Theme 3: Inconducive learning environment}

The learning environment refers to the conditions, devices, and task/time management during online learning. The following participant narratives describe the kind of learning environment they experienced: 
"The noise outside our house, from the dogs to the jeepney and car horns, sometimes disturbs me that I cannot focus in my online class, and it is difficult for me to listen during my online class." (P18)

"One of my problems in online classes is my place. I have limited space in our house because our house is small, and my siblings also have their online classes." (P21)

"My location of the connection. I need to find a place to have a better signal for me to hear the teacher. My room or in our house has a signal, but not good enough for the online class; the teacher will sound like a robot." (P16)

"I live in a remote area, and my learning environment is not good. I can't even log in to the educational apps used in the online class. Internet connection in my home was depressingly bad and turned me out of my mind. I'm in and off every time synchronous classes started." (P25)

"As a student, my online learning experience is stressful, and it's been different than what I'm used to and even busier compared to attending regular classes in person. I have been more busy than usual." (P4)

"Honestly speaking, I don't really like online school, because it makes me procrastinate to do my work last-minute. On the other hand, I finished all my assignments on time at school without feeling lazy. Also, I don't like that there are piles of homework due on the same day." (P5)

"My online learning experience as a college student is stressful. I have been swamped [more] than usual. An online class requires a lot of time and intensive work, and it is hard for me to focus on my school task, because I am a working student and I don't have enough time to do all school tasks. (P6)

The learning environment at home is not conducive to students' online learning due to limited space. The noise in the environment affects the students' learning during their online classes. Most students are disturbed by the different sounds from the environment. Noise from barking dogs, automobiles, and humans from the environment affects their hearing and learning in class. These scenarios sometimes disturb their attendance during synchronous class sessions and onlineclass participation.

Gillet-Swan (2017) claimed in her research that the one-size-fits-all approach to external students who are feeling isolated or experiencing isolation has basic problems. In comparison to their internal counterparts, these students usually have difficulty fully participating in all of the modules of their schoolwork. People enrolled in these same courses via face-to-face or blended enrolment modalities may not confront these problems, presenting a new type of learner to consider when developing and implementing online learning activities. 


\subsection{Proposed Initiative Based on the Challenges Encountered by Participants in Attending Online Classes}

In one of UNESCO's articles on the impact of COVID-19 on disadvantaged students, the chair of Culture and Education for Peace at Universidad Técnica Particular de Loja (Ecuador) stated that "at least $60 \%$ " of the student population has been affected by the pandemic (UNESCO, 2020). Many do not have the means or tools to access online teaching. Because of the enormous impact of COVID-19 on students, timely responses are necessary.

Based on the participants' expressed challenges in attending their online classes, a course pack is proposed to address the challenge of poor internet connection and limited signal. The course pack serves as the student's lesson guide. It is a collection of learning materials that supplements and provides a blueprint for accomplishing the student's reading, writing, and performance tasks. Moreover, it provides the student with an option to meet their requirements online or offline to accommodate those who have a hard time attending classes and submitting their classwork online due to their poor internet connection. Regarding allocating internet data for state university students, the course pack provided will be able to partly resolve their limited online participation. It will enable them to do their school tasks even without a connection, as long as they submit their outputs on the specified due dates.

\section{Conclusion}

University students in developing countries grappled with the challenges of connectivity issues such as poor internet connection and signal when attending online classes during the COVID-19 pandemic. This study confirmed this reality, as it found that state university students from Cebu, Philippines who participate in online courses at home are experiencing difficulty joining and attending online classes and maximizing their learning. Internet connectivity and finding a reliable signal to connect to the internet become a challenge for these students living in remote areas in the provinces, especially in the mountainous barangay areas. Moreover, students' limited economic capabilities and limited resources are also a concern they need to hurdle. They run short of money in procuring their internet pre-paid data as most of them are dependent on their family's meager income. Some of them are also working students who pay for their own studies and school expenses. Furthermore, other challenges experienced are the learning environment and learning devices used to attend online classes. Students' learning environment impedes their ability and interest to maximize their online learning experience.

\section{Recommendations}

Internet connectivity issues must be addressed with specific action plans, such as scheduling classes, activities, and assessments so students can prepare and manage their time and resources. Students need to apportion their load budget to attend scheduled activities. Teachers must also limit the number of activities and monitor students' learning outputs without sounding demanding. Likewise, research can be conducted in other schools, either private or state, or universities or colleges, to compare the research results and produce new data and 
information. Furthermore, due to some study limitations, further research is also recommended to look into the other factors that can affect students' online class experience.

\section{References}

Abeysekera, L., \& Dawson, P. (2014). Motivation and cognitive load in the flipped classroom: Definition, rationale and a call for research. Higher Education Research \& Development, 34(1), 1-14. https://doi.org/10.1080/07294360.2014.934336

Azhar, K., \& Iqbal, N. (2018). Effectiveness of Google Classroom: Teachers' perceptions. Prizren Social Science Journal, 2(2), 52-66.

https://www.researchgate.net/publication/327417783_Effectiveness_of_Google _Classroom_Teachers'_Perceptions

Saeed Al-Maroof, R. A., \& Al-Emran, M. (2018). Students' acceptance of Google Classroom: An exploratory study using PLS-SEM approach. International Journal of Emerging Technologies in Learning (iJET), 13(6), 112-123. https://doi.org/10.3991/ijet.v13i06.8275

Becker, S. P., Breaux, R., Cusick, C. N., Dvorsky, M. R., Marsh, N. P., Sciberras, E., \& Langberg, J. M. (2020). Remote learning during COVID-19: Examining school practices, service continuation, and difficulties for adolescents with and without attention-deficit/hyperactivity disorder. Journal of Adolescent Health, 67(6), 769-777. https://doi.org10.1016/j.jadohealth.2020.09.002

Braun, V., \& Clarke, V. (2006). Using thematic analysis in psychology. Qualitative Research in Psychology, 3(2), 77-101. https:/ / doi.org/10.1191/1478088706qp063oa

Burke, A. (2010). Teacher as leader in a "flat world": Preparing students in a global community. Language Arts Journal of Michigan, 25(2), 4 https://doi.org/10.9707/2168-149X.1071

CiĞerci, F. M. (2020). Slowmation experiences of pre-service teachers via distance education during the COVID-19 pandemic disease. International Online Journal of Primary Education (IOJPE), 9(1), 111-127.

Chang, C. (2016). The efficacy of a one-to-one technology initiative in improving the four Cs. Journal of Educational Technology Development and Exchange (JETDE), 9(2), 21-38. https://doi.org/10.18785/jetde.0902.02

Christensen, R. (2002). Effects of technology integration education on the attitudes of teachers and students. Journal of Research on Technology in Education, 34(4), 411-433. https://doi.org/10.1080/15391523.2002.10782359

Costley, K. (2014). The positive effects of technology on teaching and student learning. https:/ files.eric.ed.gov/fulltext/ED554557.pdf

Dhawan, S. (2020). Online learning: A panacea in the time of COVID-19 crisis. Journal of Educational Technology Systems, 49(1), 5-22. https://doi.org.10.1177/0047239520934018

Dogruer, N., Eyyam, R., \& Menevis, I. (2011). The use of the internet for educational purposes. Procedia - Social and Behavioral Sciences, 28(1), 606-611. https://doi.org/10.1016/j.sbspro.2011.11.115

Ertmer, P. A., Ottenbreit-Leftwich, A., \& Tondeur, J. (2015). Teacher beliefs and uses of technology to support 21st century teaching and learning. In International handbook of research on teacher beliefs (pp. 403-419). Routledge.

Ferri, F., Grifoni, P., \& Guzzo, T. (2020). Online learning and emergency remote teaching: Opportunities and challenges in emergency situations. Societies, 10(4), 86. https://doi.org/10.3390/soc10040086

Gebremichael, M. D., \& Jackson, J. W. (2006). Bridging the gap in sub-Saharan Africa: A holistic look at information poverty and the region's digital divide. Government Information Quarterly, 23(2), 267-280. https://doi.org/10.1016/j.giq.2006.02.011 
Geladze, D. (2015). Using the internet and computer technologies in the learning/teaching process. Journal of Education and Practice, 6(2), 67-69. https:// files.eric.ed.gov/fulltext/EJ1083835.pdf

Gillet-Swan, J. (2017). The challenges of online learning: Supporting and engaging the isolated learner. Journal of Learning Design, 10(1), 20-30. https://doi.org/10.5204/jld.v9i3.293

Heggart, K. R., \& Yoo, J. (2018). Getting the most from Google Classroom: A pedagogical framework for tertiary educators. Australian Journal of Teacher Education, 43(3), 140-153. https://doi.org/10.14221/ajte.2018v43n3.9

Iftakhar, S. (2016). Google Classroom: What works and how. Journal of Education and Social Sciences, 3(1), 12-18. https://www. jesoc.com/2016/03/KC3_35

Kamba, M. A. (2007). The internet as a tool for interactive learning, teaching, and research: The Nigerian experience. International Journal of Emerging Technologies in Learning, 2(3), 1-4. https://www.learntechlib.org/p/44904/

Kaufman, K. (2014). Information communication technology: Challenges \& some prospects from pre-service education to the classroom. Mid-Atlantic Education Review, 2(1), 1-11. https:// bit.ly/3H9CvwU

Keser, F., Akar, H., \& Yildirim, A. (2011). The role of extracurricular activities in active citizenship education. Journal of Curriculum Studies, 43(6), 809-837. https://doi.org/10.1080/00220272.2011.591433

McKnight, K., O’Malley, K., Ruzic, R., Horsley, M., Franey, J. J., \& Bassett, K. (2016). Teaching in a digital age: How educators use technology to improve student learning. Journal of Research on Technology in Education, 48(3), 194-211. https://doi.org/10.1080/15391523.2016.1175856

Morgan, H. (2020). Best practices for implementing remote learning during a pandemic. The clearing house: A journal of educational strategies, issues and ideas, 93(3), 135-141. https://doi.org/10.1080/00098655.2020.1751480

Nimrod, G. (2018). Technophobia among older internet users. Educational Gerontology, 44(2-3), 148-162. https:// doi.org/10.1080/03601277.2018.1428145

Rajab, M. H., Gazal, A. M., \& Alkattan, K. (2020). Challenges to online medical education during the COVID-19 pandemic. Cureus, 12(7), e8996. https://doi.org/10.7759/cureus.8966

Reiersgord, D. (2020). Online education during the pandemic: The challenges and opportunities. https://www.dailymaverick.co.za/article/2020-04-03-online-education-duringthe-pandemic-the-challenges-and-opportunities/

Singh, V., \& Thurman, A. (2019). How many ways can we define online learning? A systematic literature review of definitions of online learning (1988-2018). American Journal of Distance Education, 33(4), 289-306. https://doi.org/10.1080/08923647.2019

Sudarsana, I. K., Putra, I. B. M. A., Astawa, I. N. T., \& Yogantara, I. W. L. (2019). The use of Google Classroom in the learning process. Journal of Physics: Conference Series, 1175(1), 012165. https://iopscience.iop.org/article/10.1088/1742-

6596/1175/1/012165/pdf\#: :text=Google\%20classroom\%20is\%20a\%20Learning ,learning\%20for\%20digital\%20learners\%20today

UNESCO. (2020). Startling digital divides in distance learning emerge. https://en.unesco.org/news/startling-digital-divides-distance-learning-emerge

Walsh, M. (2010). Multimodal literacy: What does it mean for classroom practice? Australian Journal of Language and Literacy, 33(3), 211-239. https://www.researchgate.net/publication/267398684_Multimodal_literacy_W hat_does_it_mean_for_classroom_practice

Zalaznick, M. (2020). 3 COVID challenges hit first-generation students harder. https://universitybusiness.com/covid-challenges-hit-first-generation-collegestudents-harder/ 


\section{Appendix 1: Researcher-Made Questionnaire (in Google Forms)}

A researcher-made survey questionnaire using Google Forms was utilized as the study was conducted during the COVID-19 pandemic. The first part of the questionnaire contained items seeking data on the participants' demographic profile regarding age, gender, type of SHS they graduated from, devices used for online learning, internet service provider, and location during online learning. Part II of the instrument was a checklist of their perceived online learning challenges. The research instrument was content-validated by experts in the teaching of English. 